\title{
Characterization of the high temperature oxidation behavior of iron based alloys used as exhaust manifolds
}

\author{
G. Aktaş Çelik*, Fulya Kahrıman, Ş. Hakan Atapek and Şeyda Polat \\ Kocaeli University, Department of Metallurgical and Materials Engineering, 41380 Kocaeli, Turkey
}

\begin{abstract}
Nowadays engine capacities of vehicles spread in a wide range due to different vehicle power demands. Power density of engines affects exhaust gas and therefore exhaust gas temperature varies from $650{ }^{\circ} \mathrm{C}$ to $1000{ }^{\circ} \mathrm{C}$ in exhaust manifolds. Depending on the exhaust gas temperature, different types of iron based alloys are used as manifold materials such as ferritic ductile cast irons (GGG40, SiMo), austenitic ductile cast irons (Niresist D5S), ferritic cast stainless steels (ACIHK30, AISI 409) and austenitic cast stainless steels (CF8C). In this study high temperature oxidation behavior of different cast alloys used as exhaust manifold materials like, (i) GGG40 ferritic ductile cast iron, (ii) SiMo ferritic ductile cast iron (iii) AISI 409 ferritic cast stainless steel and (iv) CF8C austenitic cast stainless steel, were investigated.
\end{abstract}

\section{Introduction}

Vehicle power demands are spread in a wide range due to the need of different engine capacities. While some of the vehicles are designed with a small engine capacity in order to drive in city traffic, some of them are designed as performance automobiles and some are designed as heavy duty trucks. Thus, exhaust gas temperature varies from $650{ }^{\circ} \mathrm{C}$ to 1000 ${ }^{\circ} \mathrm{C}$ in exhaust manifolds due to the varying power density of engines [1-3]. Depending on the exhaust gas temperature, different types of iron based alloys are used as manifold materials. Among these alloys, ferritic ductile cast irons, and ferritic stainless steels are used at lower temperatures while austenitic ductile cast irons and austenitic stainless steels are preferred at elevated temperatures [4,5]. As ferritic ductile cast iron, GGG40 and SiMo are preferred as exhaust manifold materials. Actually, GGG40 has been used as exhaust manifold material before the development of SiMo cast iron which has higher Si and Mo content. SiMo cast iron is developed with the addition of Si and Mo elements in a standard ferritic ductile cast iron composition in order to enhance service temperature. Due to its high Si content, Si-rich oxide layer forms and acts as a barrier layer at elevated temperatures. In exhaust gas atmosphere, all these manifold materials are subjected to

* Corresponding author: gulsahaktas@gmail.com 
severe high temperature oxidation [4-6]. Ferritic cast stainless steels can be used at respectively higher temperatures than ferritic ductile cast irons and $\mathrm{Cr}$ content in their chemical composition provides higher oxidation resistance. The development of new austenitic stainless steels and Ni-resist austenitic ductile cast irons are in demand due to high thermal stability of austenitic matrix. Beside thermal stability, austenitic stainless steels have superior oxidation resistance at elevated temperatures [7-10].

In this study high temperature oxidation behavior of different cast alloys used as exhaust manifold materials like, (i) GGG40 ferritic ductile cast iron, (ii) SiMo ferritic ductile cast iron (iii) AISI 409 ferritic cast stainless steel and (iv) CF8C austenitic cast stainless steel, were investigated.

\section{Experimental study}

The chemical compositions of the studied alloys are given in Table 1 and 2. Their microstructures were characterized by light microscope (LM, Olympus BX41M-LED). Oxidation tests were carried out using thermogravimetric analysis (TGA, Netzsch), under atmospheric conditions, at $650{ }^{\circ} \mathrm{C}$, for $50 \mathrm{~h}$. Oxidation rates were determined using weight changes and oxide layers were characterized by scanning electron microscope (SEM, JEOL 6060) and energy dispersive spectrometer (EDS, IXRF).

Table 1. Chemical composition of studied cast irons (wt. \%)

\begin{tabular}{|c|c|c|c|c|c|c|c|c|}
\hline Material & $\mathbf{C}$ & $\mathbf{S i}$ & $\mathbf{M o}$ & $\mathbf{M n}$ & $\mathbf{N i}$ & $\mathbf{M g}$ & $\mathbf{P}$ & $\mathbf{S}$ \\
\hline GGG40 & 3,73 & 2,24 & 0,01 & 0,08 & 0,01 & 0,04 & 0,027 & 0,008 \\
\hline SiMo & 3,32 & 3,52 & 0,81 & 0,13 & 0,01 & 0,04 & 0,031 & 0,008 \\
\hline
\end{tabular}

Table 2. Chemical composition of studied cast stainless steels (wt. \%)

\begin{tabular}{|c|c|c|c|c|c|c|c|c|c|}
\hline Material & $\mathbf{C}$ & $\mathbf{C r}$ & $\mathbf{N i}$ & $\mathbf{M n}$ & $\mathbf{S i}$ & $\mathbf{N b}$ & $\mathbf{M o}$ & $\mathbf{N}$ & $\mathbf{T i}$ \\
\hline AISI 409 & 0,06 & 9,6 & 0,5 & 0,7 & 0,7 & - & - & - & 0,05 \\
\hline CF8C & 0,03 & 17,2 & 10,2 & 1,0 & 0,7 & 0,4 & 0,2 & 0,02 & - \\
\hline
\end{tabular}

\section{Results and discussion}

\subsection{Microstructural characterization}

The microstructures of cast alloys are given in Figure 1. GGG40 ductile cast iron is a typical ductile cast iron with globular graphite in ferritic matrix (Fig. 1a). It has been used as exhaust manifold material before the development of SiMo cast iron. SiMo cast iron has higher Si and Mo content than GGG40 cast iron, and its microstructure consists of ferritic matrix, globular graphite GGG40, Mo-rich M6C carbide and granular cementite (Fig. 1b). Due to its high Si content, Si-rich oxide layer forms and acts as barrier layer at elevated 
temperatures. AISI 409 cast stainless steel has a ferritic matrix with Ti-rich carbides (Fig.1c). CF8C cast stainless steel has $\delta$-ferrite and $\mathrm{Nb}$-rich carbides in austenitic matrix (Fig. 1d).

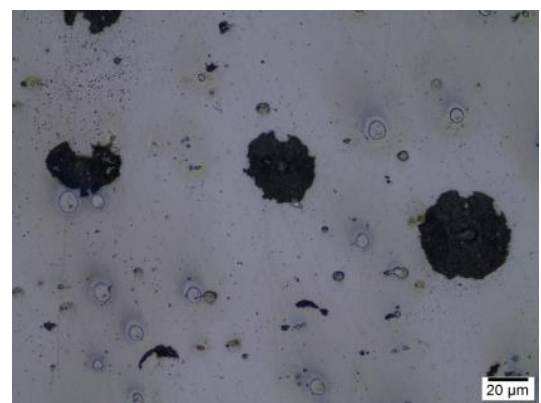

(a)

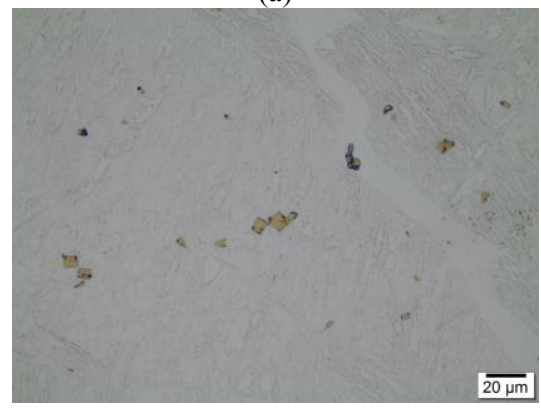

(c)

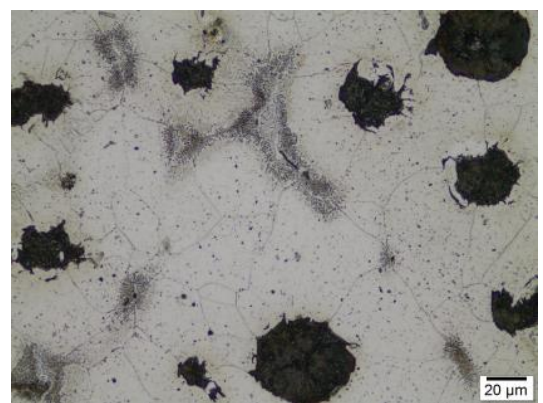

(b)

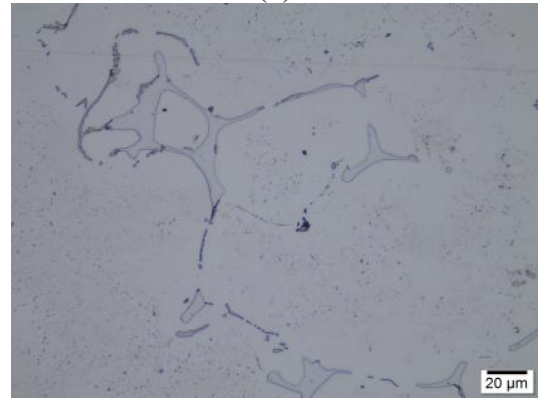

(d)

Fig. 1. LM images showing the microstructures of cast alloys (a) GGG40, (b) SiMo, (c) AISI 409, (d) CF8C.

\subsection{Evaluation of oxidation tests}

Thermogravimetric curves showing the weight changes of the experimental alloys during oxidation tests at $650{ }^{\circ} \mathrm{C}$ in air are given in Figure 2. GGG40 and SiMo ductile cast irons have higher weight changes than stainless steels. This result is expected due to the lack of or very low level of the elements which form protective oxide layers, such as $\mathrm{Cr}$ and $\mathrm{Si}$, in their chemical compositions (Table 1). As expected, SiMo has lower oxidation kinetics than GGG40 due to higher Si content in its chemical composition. Stainless steels have very low and similar weight changes at $650{ }^{\circ} \mathrm{C}$ during $50 \mathrm{~h}$ oxidation period.

SEM images showing the cross sections of oxidized alloys at $650{ }^{\circ} \mathrm{C}$ are given in Figure 3 and reveal that cast irons have thicker oxide scale than stainless steels. Among the alloys, GGG40 has the thickest oxide layer. According to literature, gray and ductile cast irons oxidizied in air have four different oxide layers. $\mathrm{Fe}_{2} \mathrm{O}_{3}$ and $\mathrm{Fe}_{3} \mathrm{O}_{4}$ form as outer layer while $\mathrm{FeO}$ and $\mathrm{FeO}+\mathrm{Fe}_{\mathrm{x}} \mathrm{M}_{\mathrm{y}} \mathrm{O}_{4}$ form as inner layer, where $\mathrm{M}$ indicates an alloying element less noble than Fe such as $\mathrm{Si}$ or $\mathrm{Cr}$ [11]. With the effect of $\mathrm{Si}, \mathrm{Fe}_{\mathrm{x}} \mathrm{M}_{\mathrm{y}} \mathrm{O}_{4}$ layer forms as $\mathrm{Fe}_{2} \mathrm{SiO}_{4}$, fayalite, on SiMo surface as inner layer. Fayalite is more protective than iron oxide layers, thus SiMo has lower weight changes than GGG40 (Fig. 2) and thinner oxide scale (Fig 3a and b). SEM/EDS studies performed on the cross-sections of oxidised alloys (Fig. 3) show that, GGG40 has the thickest oxide layer consisting of $\mathrm{FeO}, \mathrm{Fe}_{3} \mathrm{O}_{4}$, and $\mathrm{Fe}_{2} \mathrm{O}_{3}$. SiMo exhibites a Si-rich oxide layer under the mixed oxide layer of $\mathrm{FeO}, \mathrm{Fe}_{3} \mathrm{O}_{4}$, and $\mathrm{Fe}_{2} \mathrm{O}_{3}$. AISI 409 and CF8C cast stainless steels have Cr-rich oxide layer with similar thickness. 


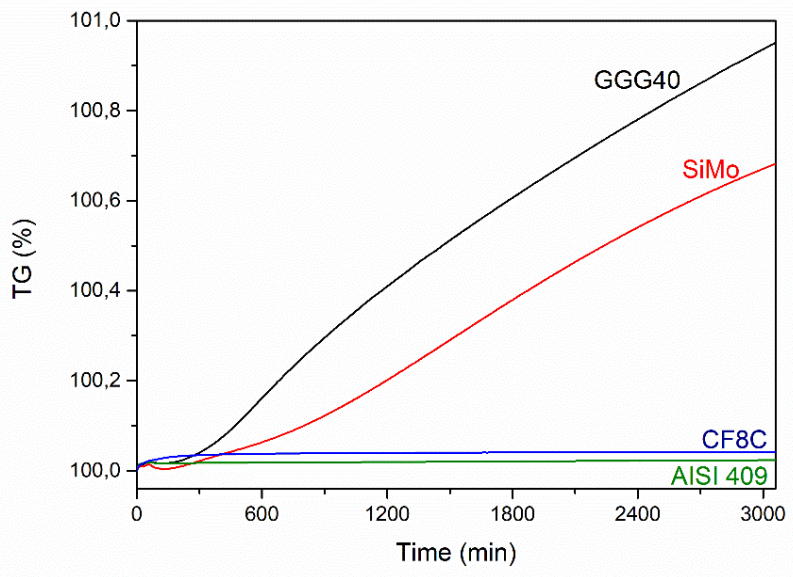

Fig. 2. Results of thermogravimetric analysis showing the weight changes for the alloys tested at 650 ${ }^{\circ} \mathrm{C}$.

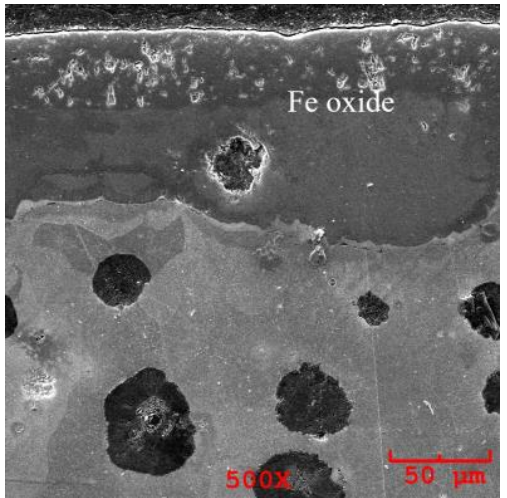

(a)

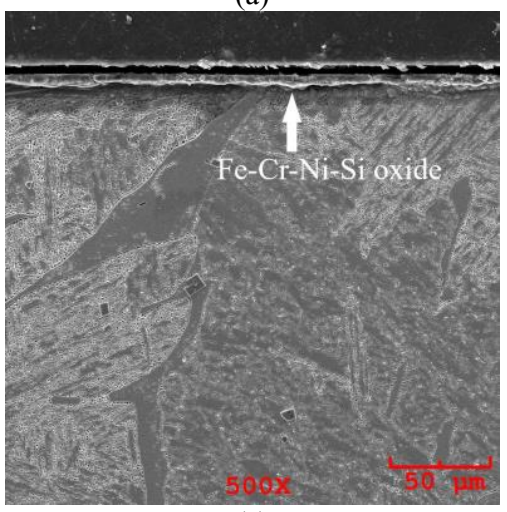

(c)

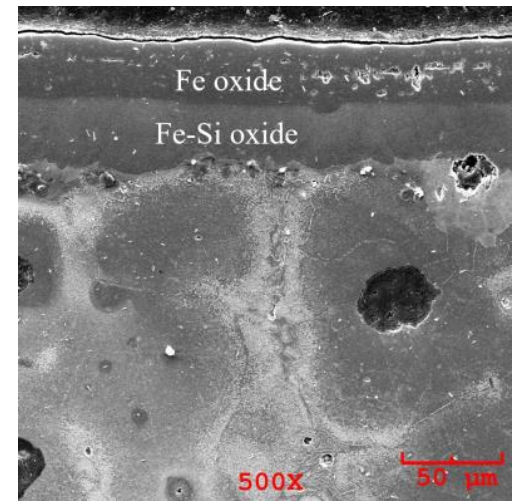

(b)

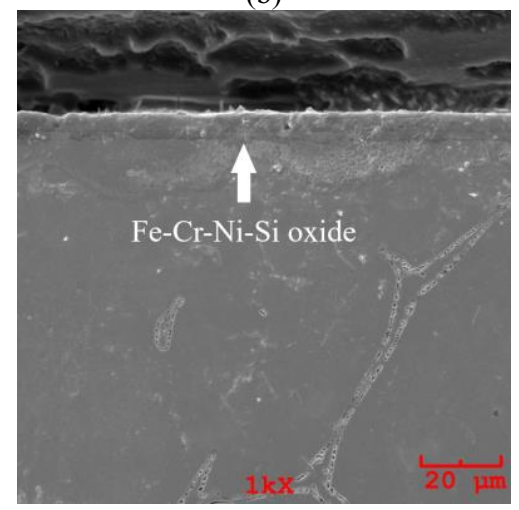

(d)

Fig. 3. SEM images showing the cross-sections of oxidised specimens; (a) GGG40, (b) SiMo, (c) AISI 409, (d) CF8C

In order to understand elemental differences in oxide scales EDS mapping images of SiMo and CF8C are given Figure 4 and 5, respectively. Due to the similar trend in oxide scales 
one alloy is chosen in each group for mapping. EDS maps show that, oxide scale of SiMo consists of $\mathrm{Fe}$, $\mathrm{Si}$ and $\mathrm{O}$ (Fig. 4). In the outer layer $\mathrm{Si}$ is weaker whereas in the inner layer $\mathrm{Si}$ becomes stronger and Fe becomes weaker. Between Si rich oxide layer and base metal, there is a smooth layer with lesser $\mathrm{Si}$ and $\mathrm{O}$ content. In literature this layer is named as attack layer [11] where oxidation progresses in base metal (Fig. 4). Oxide scale of CF8C consists of $\mathrm{Fe}, \mathrm{Cr}, \mathrm{Ni}, \mathrm{Si}$ and $\mathrm{O}$ elements (Fig. 5).
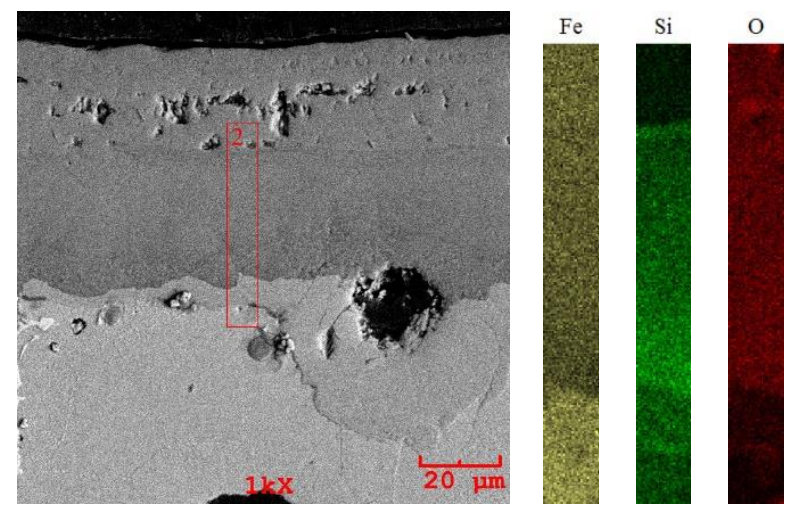

Fig. 4. EDS mapping images of SiMo.
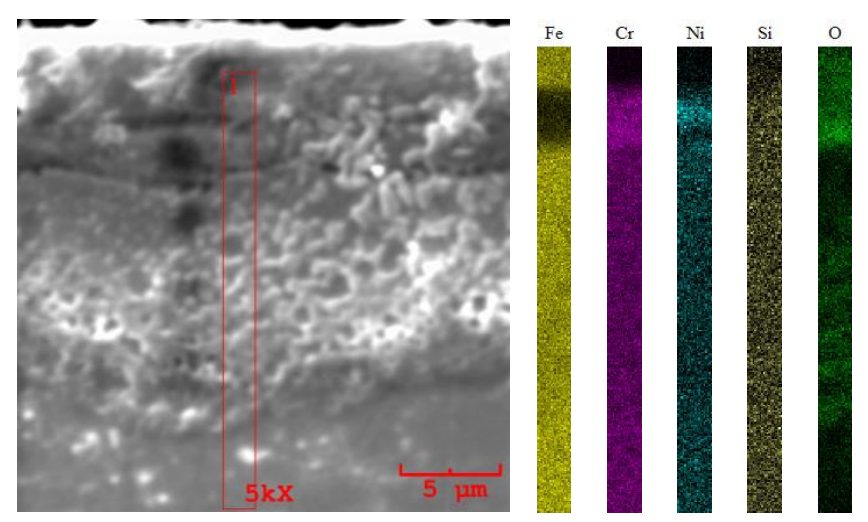

Fig. 5. EDS mapping image of CF8C

\section{Conclusion}

In this study high temperature oxidation behavior of different cast alloys used as exhaust manifold materials like, (i) GGG40 ferritic ductile cast iron, (ii) SiMo ferritic ductile cast iron (iii) AISI 409 ferritic cast stainless steel and (iv) CF8C austenitic cast stainless steel were investigated. Results indicate that, by virtue of Si-rich oxide layer, high temperature resistance of SiMo is higher than GGG40. However, Cr-rich oxide layer provides higher oxidation resistance than $\mathrm{Si}$-rich oxide layer and therefore stainless steels have lower weight changes than cast irons at $650{ }^{\circ} \mathrm{C}$ for $50 \mathrm{~h}$ exposure. 


\section{References}

1. Y. H. Zhang, M. Li, L. A. Godlewski, J. W. Zindel, Q. Feng, Materials Science \& Engineering A, 683, 195 (2017)

2. M. Ekström, S. Jonsson, Materials Science\& Engineering A, 616, 78 (2014)

3. K. Dawi, J. Favergeon, G. Moulin, Materials Science Forum, 595-598, 743 (2008)

4. M. P. Brady, G. Muralidharan, D. N. Leonard, J. A. Haynes., R. G. Weldon, R. D. England, Oxidation of Metals, 82(5-6), 359 (2014)

5. K. A. Unocic, S. Dryepondt, Y. Yamamoto, P. J. Maziasz, 47(4), 1641 (2016)

6. L. M. Aberg, C. Hartung, Transaction of The Indian Intstitute of Metals, 65(6), 633 (2012).

7. A. A. Partoaa, M. Abdolzadeh and M. Rezaeizadeh, Journal of Central South University, 24, 546 (2017)

8. M. M. Ibrahim, A. Nofal and M. M. Mourad, Metallurgical and Materials Transaction B, 48B, 1149 (2016)

9. Y. Zhang, M. Li, L. A. Godlewski, J. W. Zindel and Q. Feng, Materials Science and Engineering A, 683, 195 (2017)

10. M. Ekström, P. Szakalos and S. Jonsson, Oxidation of Metals, 80, 455 (2013)

11. F. Tholence and M. Norell, Oxidation of Metals, 69, 13 (2008) 